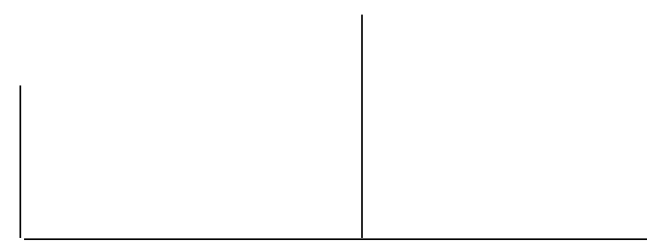

Rev. Latinoam. Psicopat. Fund., VIII, 2, 244-257

\title{
Um estudo sobre a somatose infantil em paciente portador de leucemia*
}

\author{
Aurélio Palmeiro da Fontoura Marcantonio
}

\begin{abstract}
O presente estudo propõe-se a investigar as manifestações da somatose infantil em um menino com sete anos de idade, diagnosticado leucêmico aos três anos. Utilizamos o método psicanalítico de construção de caso. Encontramos, na história subjetiva dos participantes deste caso, a presença de formações do inconsciente e formações do objeto a, envolvidas no desencadeamento e no curso da doença.
\end{abstract}

Palavras-chave: Psicopatologia somatoforme, somatose infantil, leucemia infantil.

* O caso apresentado neste artigo é um dos casos pesquisados na dissertação de mestrado "Um estudo sobre a somatose infantil em pacientes portadores de leucemia”, na Universidade Federal do Rio Grande do Sul, sob a orientação do professor Dr. José Luis Caon. 
Trata-se do caso de um menino de sete anos de idade diagnosticado leucêmico aos três. A família é constituída pelo pai, mãe e quatro filhos: um de dezoito anos, outro de dezessete, o caso, que será aqui chamado de $\mathrm{M}$, e o caçula de quatro, que será aqui chamado de $\mathrm{B}$, todos do sexo masculino. Moram numa cidade da grande Porto Alegre. O pai é empregado de uma fábrica. Conforme relato da mãe, que será aqui chamada de sra. $\mathrm{E}$, a doença retornou duas vezes desde a data em que foi diagnosticada, ou seja, houve duas recidivas. O primeiro tratamento não foi realizado até o seu final, tendo sido interrompido antes do tempo previsto por motivos não esclarecidos pela sra. E. O segundo tratamento foi levado até o final.

A história do tratamento da leucemia de $\mathrm{M}$ pode ser resumida da seguinte forma: um início de doença seguido de duas recidivas. As recidivas freqüentemente indicam que as células malignas tornaram-se resistentes às drogas ou a outro tratamento que esteja sendo usado. Estes casos tornamse mais difíceis de serem tratados. As dificuldades atuais encontradas pela terapia medicamentosa no tratamento de M relacionam-se objetivamente com os fatores citados acima. Seu prognóstico é reservado.

A manifestação da Leucemia Linfoblástica Aguda (LLA) ocorreu, no caso em questão, aos três anos de idade, estando, assim, dentro do período conhecido como crítico da leucemia, isto é, entre dois e cinco anos de idade. É precisamente nessa idade que este tipo de leucemia encontra seu pico de incidência diagnóstica no ser humano. Conseqüentemente, podemos entender que é o período em que a criança está mais exposta ou vulnerável à manifestação dessa doença. Associa-se a isso o fato de que a LLA é o câncer infantil de maior incidência (Poplack, 1989).

Foram realizadas sete entrevistas, todas com a participação da mãe e do paciente; em uma oportunidade esteve presente o irmão menor. As entrevistas ocorreram no Hospital da Criança Santo Antônio - Complexo Santa Casa, nos dias em que o paciente comparecia ao hospital para fazer exames ou quimioterapia, ou ambos. Em todas as entrevistas realizadas com $\mathrm{M}$, seu comportamento manteve-se praticamente o mesmo: muito pouco disponível, semblante fechado, não explorando o ambiente, nem mesmo respondendo às minhas perguntas e solicitações. Entretanto, o contato que tive com o paciente não restringiu-se a essas entrevistas. O tempo que 


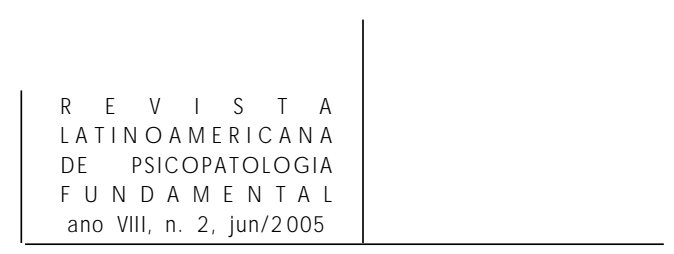

passei na sala de espera da quimioterapia oportunizou a observação da rotina e do comportamento das crianças e familiares envolvidos na situação de tratamento anticâncer no hospital. Percebi então que o comportamento e as atitudes de $\mathrm{M}$ durante as entrevistas não eram diferentes do modo como se portava em outras situações no hospital, isto é, praticamente não entrava em contato com outras pessoas, crianças ou adultos, estando, preferencialmente, no colo da mãe.

A presente investigação consiste na tentativa de conhecer melhor as circunstâncias nas quais a leucemia surgiu, conhecendo, assim, os processos subjetivos implicados na doença de $\mathrm{M}$, bem como a história que se sucedeu ao diagnóstico.

O surgimento dos primeiros sintomas da leucemia ocorreram alguns meses após a notícia de que a mãe estava grávida. Conforme relato da mesma, este foi um filho não planejado. Mais um filho a fazer parte da família e, conseqüentemente, destituir $\mathrm{M}$ do lugar de filho menor, do centro das atenções familiares. Portanto, o início da gestação coincide com a eclosão dos primeiros sintomas da leucemia. A ameaça representada pela chegada do irmão força $\mathrm{M}$ a ressituar-se na dinâmica dos investimentos familiares.

\section{A somatose e a conversão. $O$ retorno do objeto. Manifestação ou sintoma?}

O desafio ao qual nos propomos aqui é o de investigar um caso de leucemia infantil e, na medida em que os mecanismos e dispositivos da somatose introduzidos por Lacan têm origem na pesquisa freudiana do psiquismo humano, partimos, portanto, das noções freudianas que contemplam a psicopatologia somatoforme, isto é, aquela psicopatologia que assume uma determinada forma no corpo. Buscamos, assim, situar e inserir a eclosão de uma Leucemia Linfoblástica Aguda de um menino de três anos de idade em sua história de vida, que se situa na estrutura de sua família e na historia dos significantes que povoaram sua existência, dos desejos atravessados em seu corpo, e em seu sangue? Tentamos, então, resgatar este acontecimento perdido na ordem das relações simbólicas, buscando assim uma significação possível e um sentido que possa incluir as diversas variáveis e influências presentes nesta manifestação; procurar, então, pelo sentido do retorno errático do objeto foracluido para além de uma inscrição simbólica no corpo.

Um dos sintomas apresentados por $\mathrm{M}$ antes do estabelecimento do diagnóstico de leucemia foi uma dor intensa em uma das pernas. A dor aumentou a ponto de o menino ficar impossibilitado de caminhar. Os médicos inicialmente 
ARTIG O S

ano VIII, n. 2, jun/ 2005

não encontraram uma causa para a dor e conseqüentemente para as queixas de M. Um quadro como este poderia levar a crer na possibilidade de que a resposta somatoforme de $\mathrm{M}$ perante a adversidade e a desacomodação provocada pela notícia de um novo irmão, fosse uma conversão. Mas o estabelecimento do diagnóstico de leucemia alguns meses depois fez com que se descartasse a possibilidade de conversão como hipótese diagnóstica. Não há conversão na leucemia, é com a doença mesma que o paciente se depara, e não com o sintoma, ou o retorno do recalcado.

Guir (1988), em pesquisa realizada com cinco crianças leucêmicas, encontrou alguns fatores em comum nos casos. Um deles é que o aparecimento da doença coincidiu com o aparecimento na família de uma outra criança, concepção ou nascimento. Coloca que a irrupção no real destes significantes coloca a criança em sursis numa posição insustentável, desvelando-lhe assim a ausência de ancoramento simbólico em sua linhagem, precipitando então a doença.

Retomando então a pesquisa freudiana de investigação do psiquismo, produziu duas vias que tratam com maior profundidade as interações entre o psíquico e o somático. As queixas sobre o corpo ou órgão, as próprias afecções somáticas relatadas pelos seus pacientes, levaram Freud a formular duas abordagens que contemplam as manifestações que se expressam no corpo, que são a conversão histérica e a neurose atual. A distinção feita por Freud (1895) entre neuroses atuais e psiconeuroses, mesmo tendo deixado algumas dúvidas em relação às neuroses atuais, contribuiu de modo decisivo para a continuidade e para o avanço dos estudos sobre a somatose.

A conversão histérica pode ser definida, então, como a transposição de um conflito psíquico, numa tentativa de resolvê-lo em termos de sintomas somáticos motores (paralisias, por exemplo) ou sensitivos (anestesias, ou dores localizadas, por exemplo). Há, neste sentido, um vínculo simbólico entre o conflito psíquico e o sintoma. Nas neuroses atuais, o que se passa é de outra ordem. Os sintomas (manifestações da somatose) não são uma expressão simbólica e superdeterminada, mas resultam diretamente da ausência ou da inadequação da satisfação sexual. O mecanismo de formação dos sintomas em jogo nas neuroses atuais seria somático (por exemplo, transformação direta da excitação em angústia) e não-simbólico. O termo atual denota aqui a ausência daquela mediação simbólica, que encontramos na formação dos sintomas das psiconeuroses, como o deslocamento e a condensação (Laplanche, 1994).

O desejo inconsciente recalcado desempenha um papel central no mecanismo da conversão. Impedido pela força do recalque de realizar sua descarga em um objeto externo, fará com que esta descarga energética apareça no corpo. O que consiste, ainda, numa tentativa criativa de solucionar o conflito, evitando o que pode ainda ser pior. 


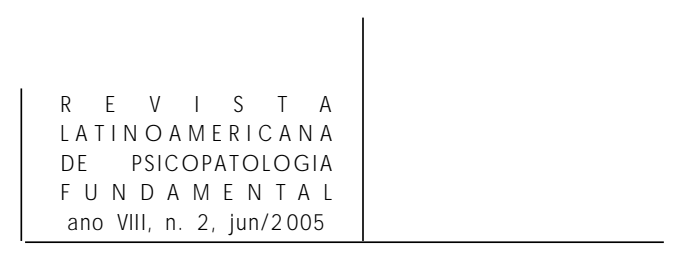

Em relação aos sintomas conversivos, na medida em que procuramos delimitá-los e diferenciá-los da somatose é importante lembrar da relação específica dos sintomas conversivos com sua significação simbólica. Da relação de compromisso entre o sintoma e sua causa. O que qualifica esse sintoma como uma formação do inconsciente e, como tal, inscrito na ordem dos significantes.

Na perspectiva em que "o inconsciente se estrutura como uma linguagem" (Lacan, 1998), podemos entender que o sintoma na conversão histérica, que aparece no corpo, tem valor de comunicação. O sintoma é, então, como um enigma. O enigma, quando decifrado, demonstra seu valor de comunicação para quem o decifra. Neste sentido, o sintoma não cessa de avisar que há um saber, inconsciente, que demanda através do sintoma, ser sabido.

A diferença fundamental que salientamos aqui entre a somatose e a conversão histérica é que esta última é determinada diretamente por uma relação na cadeia de significantes. Está inscrita, portanto, como uma formação do inconsciente (assim como os lapsos, atos falhos, chistes, o sintoma) produzida por recalcamento. No caso da somatose, temos uma manifestação que não segue as mesmas regras significantes específicas das formações do inconsciente. Tratase de uma manifestação psíquica que lança mão de outros mecanismos para sua ocorrência.

Neste sentido, Nasio (1993a) coloca o que ocorre na somatose:

... são aquelas formações psíquicas às quais as leis significantes de sucessão e de substituição não se aplicam; eu diria que são formações psíquicas nas quais não vemos as mesmas leis significantes que poderiam ser aplicadas para as formações do inconsciente. (p. 9)

\section{A teoria do significante}

No Seminário 11 (1988), Lacan lançará a questão de que, se na somatose não encontramos os mesmos mecanismos de formação dos sintomas, assim como ocorrem nas neuroses, que tipo de mecanismos estarão presentes nesta manifestação e que tipo de relação com a linguagem são estabelecidas pela mesma. Partimos da idéia de que efetivamente há relação da somatose com a linguagem. Trata-se, então, de saber como essas manifestações se articulam na linguagem. A seguinte afirmação de Lacan (ibid.) é esclarecedora do que se passa na somatose a nível dos significantes primordiais: “A psicossomática é algo que não é um significante, mas que, mesmo assim, só é concebível na medida em que a indução significante, no nível do sujeito, se passou de maneira que não põe em jogo a afânise do sujeito” (p. 187). 
ARTIG O S

ano VIII, n. 2, jun/ 2005

A citação acima é complexa e alguns esclarecimentos complementares são necessários. Nesta citação estão condensadas muitas idéias. A principal delas remete a certa especificidade na constituição da subjetividade. O significante do desejo materno e o significante Nome-do-pai são os elementos (significantes) centrais e constituintes da subjetividade humana. Lacan entende que o sujeito está dividido entre S1 (significante do desejo materno) e S2 (significante Nome-dopai), de modo que S2, significante que representa também a alteridade, opere numa ação de recalcamento sobre S1. Estes dois significantes dão origem a uma série, sendo, portanto, os dois primeiros. O encontro deste par de significantes, ou mesmo seus desencontros, equacionam forças de modo a tomar rumos e caminhos que levam a arquiteturas originais, produzindo efeitos estruturantes, determinando movimentos do sujeito psíquico.

Podemos falar pelo menos em três posições resultantes da operação entre os significantes S1 e S2. Essa distinção é fundamental para a compreensão da somatose. Nem sempre, nesta operação, ou indução significante, ocorre o corte de S2 sobre S1. Falemos, então, em três modos possíveis de ordenação dos significantes a partir da articulação de S1 com S2, isto é, da relação de S1 com o corte, que são: a) o significante S1 é recalcado (o que daria lugar à neurose); b) o significante S2 é foracluído (o que daria lugar às psicoses); c) o emassamento ou a compactação entre S1 e S2 (que daria lugar à somatose) (Nasio, 1991 e 2001).

A indução significante é esta operação que se passa entre esses dois significantes fundamentais. Qualificando de afânise (de desvanecimento, de eclipse) do sujeito a dissolução do sujeito em S2. O sujeito passa a ser representado por significantes. Ao dizer que a indução significante, no nível do sujeito, se passou de maneira que não põe em jogo a afânise do sujeito, o autor quer dizer que a operação de recalcamento de S2 sobre S1 falhou, constituindo uma estrutura distinta da organização neurótica. Neste sentido o autor afirma que a somatose é algo que não é um significante.

Tais características conferem certa proximidade da somatose em relação às manifestações psicóticas e à própria psicose, uma vez que entende-se que ambas as realidades são produzidas pelo mesmo mecanismo: a foraclusão. A somatose, contudo, não é uma psicose. Uma realidade formada por foraclusão pode tomar dois diferentes rumos. Um, onde domina a dispersão produzida pela liberação de cada elemento de sua ligação à cadeia, o que corresponde ao ego fragmentário do psicótico; e, outro, onde domina a solidificação de todos os significantes, que corresponde à alucinação e à somatose. A solidificação, em sua origem, sustentase na hipótese de que o intervalo entre S1 e S2 é suprimido e o par, desprovido de sua articulação, solidifica-se em uma espécie de apreensão em bloco comum (Nasio, 1991). 


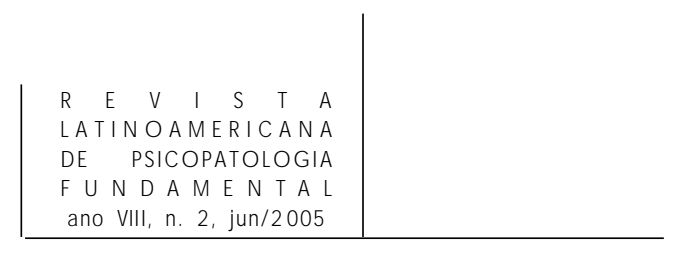

É importante situar um contexto familiar que diz respeito à história de $\mathrm{M}$, a história que antecede seu nascimento. Sabemos que o desejo dos pais pelo filho que está para nascer é constituinte do lugar onde este será acolhido pela demanda daqueles. Fundamental, portanto, no processo de constituição do sujeito e subjetivação em qualquer um. A história que antecede o nascimento de $\mathrm{M}$, segundo nos relata sua mãe, é muito significativa. A família em questão esperou cinco anos por esta gravidez. M foi um filho muito esperado e desejado. Em uma das entrevistas a mãe disse que não entendia porque isso tinha acontecido (a leucemia), pois desejaram esta gravidez por cinco anos, "foi um filho muito esperado, e aconteceu isso, deu errado, tudo errado". Neste momento ela pede a confirmação de M, que está no seu colo: “Não é M?” E M acena com a cabeça afirmativamente.

Sua resposta frente a esta demanda materna foi direta e incondicional. Percebe-se no seu ato que se trata mais de um responder com a mãe do que um responder para a mãe; além disso, uma resposta sem palavras, veiculada pelo corpo. A passagem acima também caracteriza a intensidade do vínculo materno sobre este filho tão esperado, mas não somente a intensidade deste vínculo, como seu caráter atual de ambivalência. Atual em relação à doença do filho. "Tudo certo" e "tudo errado" confundem-se nos ditos maternos. O filho é solicitado, então, a confirmar esses ditos, mais do que isto, confirmar também o lugar daquele que é destinatário e depositário destes investimentos ambivalentes.

Dentre os dados mais importantes obtidos a partir das entrevistas, encontramos, na questão da amamentação e do conseqüente desmame, dados relevantes que, entendidos no seu contexto de origem, são muito significativos no sentido em que se encontre elementos sobre a constituição psíquica do sujeito. $\mathrm{O}$ que constatamos neste caso foi um desmame não efetivado. M só deixou de ser amamentado quando nasceu seu irmão. Nesse período estava com aproximadamente três anos de idade. Com o nascimento do irmão, ficou sem mamar por um mês. Contudo, um mês após o nascimento $M$ voltou a mamar junto ao seio materno e junto com o bebê. Soma-se a isto o fato de que o paciente nunca deixou efetivamente de dormir no quarto dos pais. Atualmente o filho menor (B) dorme no quarto com os irmãos maiores. São informações que trazem elementos importantes, permitindo compor e entender melhor o funcionamento familiar e o universo psíquico desta criança, bem como a qualidade do vínculo estabelecido pela mãe, fundante do psiquismo do bebê.

Outro acontecimento significativo no desenrolar dos fatos familiares refere-se à morte da avó materna. Isto ocorreu quando o filho menor tinha dez meses. $\mathrm{O}$ período coincide com o desmame definitivo de $\mathrm{M}$. As informações sobre a morte da avó materna e a relação deste fato com o desmame de M são pouco precisas e mais dedutíveis do que propriamente explicitadas nas falas da sra. E. Su- 
gere, entretanto, que a castração imposta pelo desmame esteja mais relacionada com o luto conseqüente da morte da avó, do que com uma atitude calcada no entendimento da necessidade da separação, operada pela castração imposta pelo desmame.

Esta investigação, a partir do par significante (S1, S2), propõe um olhar ao início, à origem e à estrutura. Um objeto $a$, emergente, que nasce e não cessa de mostrar seu resto na realização de cada desejo; e de uma somatose, psicogeneticamente traçada e instalada potencialmente, que convive no sujeito como um dispositivo a seu alcance que em algum momento, num determinado momento, pode ser acionado. Seu acionamento dispara um mecanismo, que tem como uma de suas realizações a lesão de órgão.

\section{As formações do objeto $a$ e seus retornos}

Uma contribuição original de Lacan de extrema relevância para a psicanálise foi a formulação do conceito de objeto $a$ : objeto do desejo e objeto causa do desejo. Dentre outras conseqüências desta noção, talvez uma das mais importantes tenha sido a possibilidade do entendimento de que o psiquismo não se resume às articulações significantes, como, por exemplo, o sintoma.

Quando dizemos que a somatose não responde às mesmas leis significantes que operam nas formações do inconsciente, segundo Nasio (1991), está sendo referido o processo de formação da manifestação da somatose. O mecanismo de formação da somatose, segundo esta perspectiva, é semelhante ao mecanismo que produz a alucinação, ou seja, a foraclusão. Aqui, não devemos confundir psicose com foraclusão, a psicose é um estado, uma posição na estrutura e a foraclusão é um mecanismo. Um mecanismo de exclusão do simbólico e do significante Nome-do-pai. Diferenciando, então, as formações do inconsciente das formações do objeto $a$.

As formações do objeto $a$ são situadas por Nasio (1993a) como aquilo que é heterogêneo à rede do conjunto significante. Ou seja, o sistema produz alguma coisa excedente que lhe é heterogênea ou estranha. A ordem simbólica significa que todos os seus componentes, inclusive aquele que constitui seu limite (S1), são homogêneos, isto é, todos são regidos pelas leis da lógica significante. Já as formações do objeto $a$, ao contrário, é o único a escapar a essa lógica. Está claro, então, que o objeto $a$ é excedente e heterogêneo às leis da lógica do significante.

A via de retorno é, neste caso, muito particular: um sujeito não dividido, mas fragmentado ou compactado, acolhe e percebe um objeto errático. A trama do meio que circunda o objeto e onde se opera a percepção tem uma outra estrutura que não aquela do meio recalcante, e isto porque a operação dominante aqui é a 


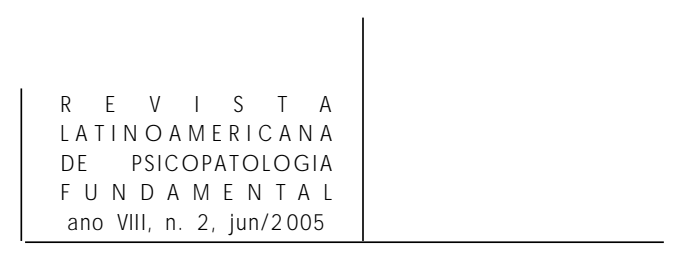

foraclusão. Considerando o caráter forclusivo do meio, chamamos esta formação de formação de $a$ produzida por foraclusão (Nasio, 1991). A questão do retorno do objeto na somatose será retomada no decorrer do texto.

Tanto a alucinação, como o acting out e a somatose são "formações do objeto $a$ ” e estão, portanto, relacionadas com a dimensão do fazer. Neste sentido, o sujeito faz sem saber o que faz. Já a comunicação na neurose é significante, estando, portanto, relacionada a um “dizer”. A comunicação na somatose é um "ato", um fazer no corpo. O corpo é tomado por algo que não faz significação para o sujeito; conseqüência disso é a idéia de que o que lhe ocorre é totalmente independente de si, portanto tomado por algo externo a si. Entendemos, então, que se trata de um objeto errático, do retorno de um objeto errático.

Esse sujeito fragmentado é aquele que, na base de uma foraclusão, identificase com o objeto errático $a$, que retorna de longe. Esta distância entre o sujeito e o objeto é tal que o sujeito não chega a encontrar-se diante do objeto, ele se torna o objeto. O sujeito fragmentado ou compactado, por oposição ao sujeito dividido da fantasia, é aquele sujeito que acolhe o objeto de seu desejo através do ato de um outro e, portanto, sem o intermédio de um significante.

\section{Os ditos maternos e o inconsciente estruturado como uma linguagem.} Do dizer ao fazer

A pesquisa de Nasio desenvolve-se a partir da escuta clínica de seus pacientes, estabelecendo, assim, uma relação específica da pesquisa psicanalítica com a transferência. A clínica é o grande laboratório de pesquisa do pesquisador psicanalítico e onde a transferência ocupa um papel fundamental. O autor distingue dois tipos de transferência: aquela que evoca acontecimentos significantes e aquela que evoca acontecimentos não-significantes. A primeira move-se na matriz da transferência linguageira, e a segunda na matriz da transferência não linguageira. A matriz linguageira é aquela que está ao nível do dito, como o lapso, articulada na lógica do significante. A matriz não linguageira é aquela que está ao nível do fazer, como a somatose, por exemplo. Ao estabelecer as diferenças entre essas duas dimensões, a do dito e a do fazer, Nasio (1991) propõe a distinção entre as formações do inconsciente das formações do objeto $a$, onde a dimensão do dito é a redução ao plano do inconsciente e a dimensão do fazer, a redução ao plano do objeto $a$, o que está claro na seguinte passagem:

O dito e o fazer se realizam sem seu conhecimento e, de algum modo, fora deles, excêntricos tanto ao analista quanto ao paciente. Assim, caracterizamos as formações do inconsciente como inscritas na dimensão do dito (dit-mension): o 


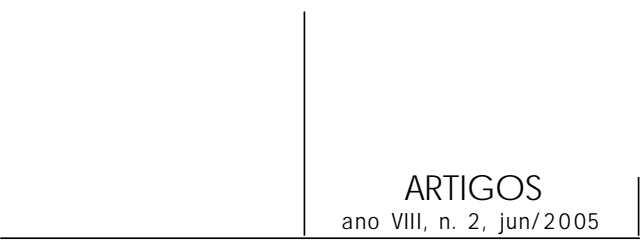

sujeito diz sem saber o que diz; e caracterizamos as formações do objeto a como inscritas na dimensão do fazer (faire-mension): o sujeito faz sem saber o que faz. (p. 53-4)

Uma passagem da primeira entrevista caracteriza, ainda que inicialmente, o modo como a sra. E concebe o filho doente. Ao falar da história de M, disse que ele foi um filho muito esperado e desejado pelos pais, mas que tinha dado tudo errado. Refere-se, portanto, à mudança subjetiva causada pelo diagnóstico da doença, a qual parece ter provocado a passagem de uma situação onde "está tudo bem” para uma situação onde “está tudo errado”. Quando fez esta afirmação, deu muita ênfase ao aspecto do erro. Filho, doença e idéia de erro apareceram quase sem distinção em sua fala.

O filho estava presente quando a mãe fez esta colocação, tendo sido solicitado pela mesma a confirmar que "tudo estava errado”. Há uma certa dose de agressividade nesta atitude da sra. E, no modo de colocar direta e abertamente sua insatisfação com a realidade implicada pela doença na presença do filho. Não temos dúvida de que se trata de uma situação muito difícil de enfrentar. Entretanto, o que nos parece importante aqui é observar o modo como esta realidade é enfrentada, e como o filho é situado nesta mudança de realidade.

O discurso que diz estar o filho muito bem, que tudo está bem, situa-se no extremo oposto da afirmação de que tudo deu errado. São falas antitéticas que fazem parte de um mesmo discurso. Entretanto, o importante é observar e escutar a fragilidade deste mesmo discurso. Sua sustentação está comprometida por “ditos” que interrompem bruscamente sua linearidade, introduzindo elementos novos, reveladores e até mesmo chocantes em sua essência.

$\mathrm{Na}$ última entrevista, a sra. E reforça um aspecto já mencionado, que faz pensar acerca de que filho ou de que representação de filho fala esta mãe. Ao ser perguntada sobre o estado de $\mathrm{M}$ e o tratamento, responde, basicamente, com duas afirmações. Afirmações estas excludentes entre si: a primeira é de que $M$ “está indo muito bem... está super bem”, e a segunda que, devido à baixa das defesas, a quimioterapia está suspensa até que estas retornem a um nível que permita ao corpo tolerá-la. Deve ir duas vezes por semana ao hospital fazer exame de sangue e consultar com o pediatra até que a situação se normalize.

A contradição na postura da sra. E é visível; com um quadro clínico grave e preocupante, como descrito anteriormente e confirmado pela equipe médica, quem está bem? De que filho está esta mãe falando?

Podemos pensar na possibilidade de que a sra. E não conseguiu fazer o luto pelo filho que ela perdeu ao receber o diagnóstico da doença. Por este motivo evoca com freqüência a idéia de que o filho está muito bem; mas afinal, como pode ele estar bem? Só pode estar referindo-se àquele filho antes do diagnóstico,

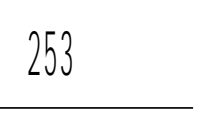




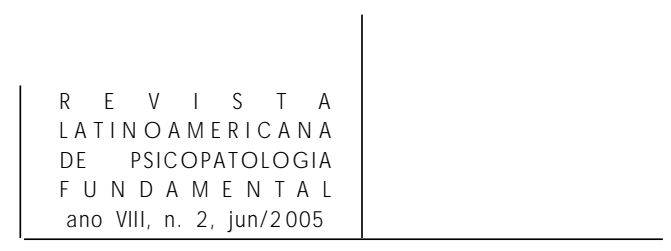

que só pode continuar agora como um filho imaginário e não o filho diagnosticado. Não estaria a sra. E narcisicamente impedida de aceitar a doença do filho, e, conseqüentemente, um filho doente, reagindo com agressividade a esta realidade que não suporta?

M continua sendo tratado como um bebê por sua mãe, isto é, ela quer que ele continue sendo o seu bebê e é neste lugar que o espera; ele, aparentemente, corresponde a esta demanda. Chamamos atenção para a primeira entrevista onde foi registrada a seguinte passagem: “A mãe passa B (o filho menor) para a cadeira vaga ao lado e puxa $M$ para seu colo, interrompe o que dizia e diz: este aqui (M) é mais bebê que o menor (B), não é $M$ ? E M movimenta a cabeça para cima e para baixo duas ou três vezes, confirmando a mãe”.

Dois trechos de uma entrevista gravada e transcrita ilustram muito bem o modo de ruptura discursiva na linguagem falada. Mas estas passagens revelam muito mais do que isto, é o próprio "isso" (o inconsciente) que se manifesta na fala da mãe em nome de uma verdade. Verdade que só aparece despercebida e velada. A primeira passagem ocorreu após o pesquisador pedir para que explicasse ao que atribui a doença do filho. As passagens são as que seguem:

Antes achava que eu não tinha saída. Hoje eu digo para ti com toda a certeza, porque eu sempre soube, sempre fica em minha cabeça que o $\mathrm{M}$ vai viver. Eu não tenho nenhum pensamento positivo. O meu filho já passou por várias situações difíceis e eu nunca vi o pior para ele. Confio em Deus. Porque certas mães vêem que eles não estão bem e entregam os pontos, eu não entrego os pontos. Confio em Deus. Eu tenho certeza que o $M$ vai viver, vai sair dessa de novo, essa doença vai curar. Ela já curou uma vez, ela tem que curar outra vez para nunca mais voltar.

Na mesma entrevista, encontramos também esta passagem, quando a sra. E foi questionada sobre a aceitação da medicação por M:

Eu digo para ele: M está na hora do remédio, ele abre a mãozinha assim, eu coloco vinte comprimidos na mão dele, aí eu digo, vamos tomar cinco e depois mais cinco... Ele diz: Não, vou tomar todos de uma vez, aí vai mais rápido. Eu coloco na mãozinha dele e ele toma. Ele não tem problema nenhum para tomar a medicação. Ele ajuda muito sabe. O M quer viver. É este o problema. Eu digo assim para ele: $\mathrm{M}$ eu vou te dar este chá aqui, tu toma e vais sarar. Ele toma, não diz nada. Se tem de tomar ele toma. Ele faz tudo como eu digo para ele.

Seus “ditos” confirmariam a hipótese de que a mãe não se desprendeu da imagem do filho que tinha antes do diagnóstico, uma vez que os “ditos” expressam toda uma impossibilidade dela em reconhecer este filho assim como a realidade mostra, portador de uma doença grave. Portanto, o filho que ela deseja 
parece ser aquele antes do diagnóstico e não a criança que conhecemos. Neste sentido, para a mãe, a realidade é outra, a que ela deseja, modelada à sua imagem, em detrimento da realidade objetiva.

As falas da sra. E revelam um dilema que se coloca entre a vida e a morte, entre um filho real e outro representado, que colocamos nos seguintes termos: $\mathrm{O}$ filho diz: “quero viver”. A mãe responde: “é este o problema”. Quando a linguagem falada e significante diz que viver é um problema, pensamos na possibilidade do corpo do outro responder com seu próprio corpo. Perguntamonos também se a idéia de que "viver é um problema" é algo que foi introduzido na vida do paciente a partir do diagnóstico, ou se viver sob uma demanda povoada pelo narcisismo materno, que determina um lugar muito específico para este filho, constitui também um problema para a vida?

\section{Considerações finais}

Podemos afirmar, a partir de certos dados já citados, que indicam ou sugerem que M não foi desmamado, isto é, não recebeu este limite constitutivo produzido pela eficácia do recalque. Limite que consiste também em produzir subjetividade e diferenciar os corpos. Neste sentido, a perda do objeto de sucção, o seio, coloca a possibilidade de que o investimento se dirija para outros objetos. Seriam estes indícios de uma castração que não operou ou operou precariamente? E mesmo dizer que não houve queda do objeto para emergência do objeto $a$ ?

Reunimos aqui três fatos ou três atitudes da sra. E que apontam para uma mesma direção. Percebemos algo em comum nestes acontecimentos, nos dizeres, no desmame que não ocorreu e na mudança de quarto que também não ocorreu, uma vez que remetem a um fato em comum, a dificuldade da separação e corte na relação mãe-filho. Parecem estar ligados por uma relação fusional. É como se esta mãe dissesse: "Tu continuarás sendo meu bebê"; "mames incondicionalmente"; ou seja, trata-se de um desmame que nunca foi realizado, e, conseqüentemente, uma castração que não se realizou.

Se tomamos o desmame como um processo, logo situamos os protagonistas deste processo em relação ao que se espera de suas respectivas funções ou lugares. Em relação ao que foi observado no caso, esse revela mais do que os fatos sobre o desmame, mais os sujeitos em questão.

Entendemos que os fatos citados acima são constituintes no que se refere à possibilidade de compactação entre S1 e S2. Trata-se de uma situação na qual podemos dizer que na indução significante não houve uma afanização do sujeito, isto é, o recalcamento de S2 sobre S1 falhou. 


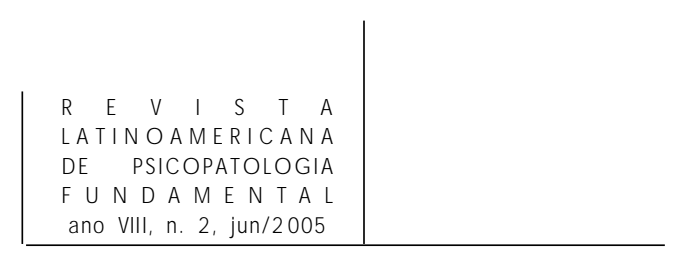

A hipótese para este caso é de que a notícia da chegada de mais um irmão operou como fator desencadeante da leucemia, a partir dos mecanismos psicopatológicos da somatose, ou seja, operou uma foraclusão local, conseqüência do emassamento dos significantes S1-S2.

A irrupção no real destes significantes coloca a criança em sursis numa posição insustentável, desvelando-lhe assim a ausência de ancoramento simbólico em sua linhagem, precipitando então a doença (Guir, 1988). Parece haver uma relação de proporcionalidade entre a intensidade do vínculo (fusional) e a intensidade do impacto da gravidez da mãe. A maior vulnerabilidade do psiquismo infantil é outro fator que soma-se ao impacto da descarga direta no corpo real. O sujeito compactado é aquele sujeito que acolhe o objeto de seu desejo através do ato de um outro. Seu corpo reage ao ato do outro, este ato, aqui, é a notícia de que teria mais um irmão.

A somatose, assim como proposta por Lacan nos Seminários livro 2 e livro 11, é entendida como uma impossibilidade de articulação simbólica dentro da cadeia de significante que se interromperia diante de um real insuportável, um apelo significante que levaria a um emassamento ou fusão do par significante S1/S2 resultando numa inscrição no real do corpo. Poderíamos pensar na hipótese de que a somatose ocorre quando o sujeito leva muito longe a barreira do gozo. Tal efeito pode ser conseqüência de falha no processo de recalcamento. Neste sentido, Souza (1998) coloca que "o sujeito não goza mais com as formações do inconsciente, com os significantes do sujeito submetido à lei da castração, mas goza com o eczema, com a úlcera, com o câncer...”

\section{Referências}

Chemama, R. Dicionário de psicanálise. Porto Alegre: Larousse-Artes Médicas, 1995. Freud, Sigmund (1895). Sobre os critérios para destacar da neurastenia uma síndrome particular intitulada neurose de angústia. In: Edição Standard Brasileira das Obras Psicológicas Completas. Rio de Janeiro: Imago, 1974.

Guir, Jean. A psicossomática na clínica lacaniana. Rio de Janeiro: Jorge Zahar, 1988.

LaCAN, Jacques. A instância da letra no inconsciente ou a razão desde Freud. In: Escritos. Rio de Janeiro: Jorge Zahar, 1998.

O seminário. Livro 11. Os quatro conceitos fundamentais da psicanálise. Rio de Janeiro: Jorge Zahar, 1988.

Laplanche, L. e Pontalis, J.-B. Vocabulário da psicanálise. São Paulo: Martins Fontes, 1994. 


\section{ARTIG OS}

ano VIII, n. 2, jun/ 2005

Nasio, Juan-David. Cinco lições sobre a teoria de Jacques Lacan. Rio de Janeiro: Jorge Zahar, 1993.

Los gritos del cuerpo. Psicossomática. Buenos Aires: Paidós, 2001.

Psicossomática. As formações do objeto a. Rio de Janeiro: Jorge Zahar, 1993.

Os olhos de Laura, o conceito de objeto a na teoria psicanalítica. Porto Alegre: Artes Médicas, 1991.

Poplack, D. G. Principles and Practice of Pediatric Oncology. J. B. EUA: Lippincott Company, 1989.

SouzA, M. L. Anorexia, psicossomática, pulsão. Pulsional Revista de Psicanálise, São Paulo, ano XI, n. 106, p. 39-47, fev./1998.

\section{Resumos}

El presente estudio se propone investigar las manifestaciones de la somatosis infantil en un niño de siete años de edad, diagnosticado leucémico a los tres años. Utilizamos el método psicoanalítico de construcción de casos. Encontramos, en la historia subjetiva de los participantes de este caso, la presencia de formaciones del inconsciente y formaciones del objeto a, involucradas en el desencadenamiento y en el curso de la enfermedad.

Palabras claves: Psicopatología, somatoforme, somatosis infantil, leucemia infantil

Cet article consiste en une investigation des manifestations de la somatose infantile chez un petit garçon de sept ans souffrant d'une leucémie diagnostiquée à l'âge de trois ans. Nous avons utilisé la méthode psychanalytique de la construction du cas. Nous avons pu observer, dans l'histoire subjective des participants de ce cas, la présence de formations de l'inconscient et de formations de l'objet impliquées dans le déclenchement et l'évolution de la maladie.

Mots clés: Psychopathologie somatoforme, somatose infantile, leucémie infantile

The present study aims to investigate the manifestations of childhood somatosis in a 7 year old boy, diagnosed when he was three. The investigation was based on the psychoanalytic method of case studies. In this case, the presence of unconscious formations and object a formations were identified in development of the sickness and in the subjective stories of the interviewed participants.

Key words: Somatoform psychopatology, childhood somatosis, childhood leuquemia

Versão inicial recebida em outubro de 2004

Aprovado para publicação em fevereiro de 2005 